\title{
O SOFT POWER DO BRASIL E A COBERTURA DA MÍDIA INTERNACIONAL DA COPA DO MUNDO DA FIFA 2014 ${ }^{1}$
}

\author{
Recebido em: 19/07/2017 \\ Aceito em: 12/03/2018 \\ Marco Bettine Almeida ${ }^{2}$ \\ Diego Gutierrez ${ }^{3}$ \\ Universidade de São Paulo \\ São Paulo - SP - Brasil
}

RESUMO: Este artigo tem como objetivo apresentar uma reflexão sobre o impacto que a realização da Copa do Mundo da FIFA de 2014 pode ter sobre o Soft Power do Brasil em suas relações internacionais. Para tanto, desenvolveu-se a definição de Soft Power associando-a aos megaeventos esportivos. Pesquisou-se nove veículos de imprensa internacional em três idiomas diferentes $(\mathrm{BBC}, \mathrm{CNN}$, The Guardian, The New York Times, Daily Mail, Le Monde, Le Figaro, El Pais, El Mundo). Analisou-se e categorizou-se 699 reportagens em seis grandes temas geradores: infraestrutura, indicadores sociais, cultura, futebol, viabilidade da Copa, cenas do cotidiano. Concluise que a realização da Copa do Mundo FIFA de 2014 teve efeitos positivos nas áreas do espetáculo esportivo e da cultura brasileira voltada ao turismo, e efeitos negativos nas áreas: política (como o Estado trata os cidadãos nas manifestações políticas), sociais (saneamento básico, educação, saúde) e estruturais (brasis dos extremos).

PALAVRAS CHAVE: Brasil. Relações Internacionais. Futebol.

\section{THE SOFT POWER OF BRAZIL AND THE FIFA'S 2014 WORLD CUP INTERNATIONAL MIDIA COVERAGE}

ABSTRACT: This article aims to present a reflection on the impact that the realization of the 2014 FIFA World Cup may have on Soft Power of Brazil in its international relations. For that, the definition of Soft Power was developed associating it with the sports mega events. Nine international media outlets were searched in three different languages (BBC, CNN, The Guardian, The New York Times, Daily Mail, Le Monde, Le Figaro, El Pais, El Mundo). 699 reports were analyzed and categorized into 6 major generating themes: infrastructure, social indicators, culture, football, Copa feasibility, daily scenes. It is concluded that the 2014 FIFA World Cup had positive effects in the areas of sporting spectacle and Brazilian culture geared to tourism, and negative effects

\footnotetext{
${ }^{1}$ Pesquisa Financiada pela FAPESP.

${ }^{2}$ Professor Livre Docente da Escola de Artes, Ciências e Humanidades da Universidade de São Paulo.

${ }^{3}$ Graduado em Jornalismo da Escola de Comunicação e Artes (USP). Mestre em Ciências pelo Programa de Pós-graduação em Mudança Social e Participação Política (EACH-USP).
} 
in the areas of politics (as the State treats citizens in political manifestations), social (Sanitation, education, health) and structural (extreme Brazil).

KEYWORDS: Brazil. International Relations. Soccer.

\section{Introdução}

Os pesquisadores brasileiros de distintas áreas do conhecimento tiveram (e têm) muitas nuances para analisar o Brasil dos megaeventos, foram escritos textos sobre viabilidade, protestos, gentrificação, financiamento, legado (ROLNIK, 2016; DAMO, 2016; ALMEIDA e BASTOS, 2016) -, acreditamos que o mundo acadêmico tem se debruçado com afinco sobre estes acontecimentos e daqui por diante necessitaremos de trabalhos transversais que demostrem com seriedade e distanciamento, se de fato um país com problemas radicais em áreas como saúde, educação, saneamento básico, segurança, fome, moradia e emprego (com direitos), deve fazer um esforço hercúleo para sediar os megaeventos.

Feito esta pequena introdução, gostaríamos de apresentar onde este trabalho se encaixa neste espectro de possibilidades que os megaeventos propiciam como um locus de contradições no capitalismo avançado.

Este texto busca oferecer ao leitor a imagem que o Brasil construiu no exterior durante a Copa do Mundo de 2014 por meio da mídia internacional (a cobertura jornalística dos principais jornais do ocidente). A ideia deste artigo é analisar os efeitos nas relações internacionais ao sediar os megaeventos utilizando como categoria de análise o Soft Power, perguntando: o megaevento oferece de fato, aos países sede, oportunidades de se ingressarem como um porta voz político representando uma região? No caso do Brasil, a tão sonhada cadeira permanente no Conselho de Segurança da ONU pode ser conquistada com ações políticas internacionais como são os megaeventos 
esportivos? Podemos afirmar que a pesquisa não chegou a repostas categóricas, no entanto, foi possível construir um cenário sobre o olhar do outro no período do megaevento. Foi possível enxergar e estranhar fatos que passaram despercebidos, e ver o Brasil a partir do referencial do estranho e tornar o estranho inteligível.

Para trilhar este caminho, pesquisou-se nove veículos de imprensa internacional em três idiomas diferentes (francês, espanhol e inglês). As mídias foram escolhidas pelo número de pessoas que visitam o site e os tem como fonte de informação, foram eles, a BBC, a CNN, o The Guardian, o The New York Times, o Daily Mail, o Le Monde, o Le Figaro, o El Pais e o El Mundo.

Ao todo foram analisadas 699 reportagens. O período de análise escolhido foi entre os dias 11/06 e 15/07, três dias antes de iniciar a Copa do Mundo de 2014 até três dias depois de terminada. Os artigos, tratados metodologicamente, discutiam questões sociais, políticas e econômicas do Brasil durante a Copa do Mundo - artigos relacionados ao futebol como lesões, táticas, resultados, previsões, entrevistas com jogadores foram descartados. Buscamos, com isso, entender quais foram as caracterizações do Brasil mais presentes durante a Copa do Mundo, que tipo de preconceitos e mistificações a imprensa estrangeira iria apresentar sobre o Brasil e quais seriam as eventuais mudanças que o evento desta magnitude trariam para a imagem do país no exterior e se elas possibilitariam ao Brasil incrementar o seu Soft Power.

\section{Soft Power na Política Internacional}

Joseph S. Nye Jr, em 1990, no seu livro "Bound to Lead: The Changing Nature of American Power", e depois em uma série de artigos e outras publicações (NYE, 1990b, 2004) reinterpretaria a noção de poder na política internacional, dividindo-o em 
duas grandes categorias, Hard e Soft, termos que se consagraram, tanto na academia quanto na própria política, sendo inclusive tema de discursos dos mais variados líderes internacionais, como $\mathrm{Hu}$ Jin Tao em 2007, quando, no $17^{\circ}$ congresso do partido comunista, se referiu à necessidade da China aumentar o seu Soft Power (HUANG, DING, 2006; DING, 2010).

A noção de Hard Power pode ser definida, de uma maneira direta, como sendo a capacidade de coerção de uma nação sobre as outras, descrita por Nye como incentivos e ameaças. Os estudos do Hard Power irão se focar no poder militar, econômico e ameaças diplomáticas como ferramentas para um estado conseguir seus objetivos (CAMPBELL; MICHAEL, O’HANLON, 2006).

Diferentemente, Soft Power é definido (NYE, 1990a, p.12) como a forma de um país obter resultados na política internacional, porque os outros países admiram seus valores, aspiram ao seu nível de prosperidade e acabam por segui-lo ${ }^{4}$.

Para o autor, o poder nas relações internacionais é a capacidade de um país conseguir os resultados que lhe interessam na política internacional, o que pode ser feito por meio da coerção (Hard Power) ou da cooptação (Soft Power) (KEOHANE; NYE, 1977).

Os críticos do Soft Power irão atestar a dificuldade para dissociar o Hard do Soft, ou quanto de cada elemento existe na influência real de um país e o fato de que é impossível acompanhar a inter-relação entre eles. Respondendo às críticas, Nye (2004), e outros teóricos, formularam a categoria Smart Power, que é a utilização combinada de elementos Hard e Soft (WILSON, 2008).

\footnotetext{
${ }^{4}$ A country may obtain the outcomes it wants in world politics because other countries -admiring its values, emulating, its examples, aspiring, to its level of prosperity and openness- want to follow it. In this sense, it is also important to set the agenda and attract others in world politics, and not only to force them to change by threatening military force or economic sanctions. This Soft Power- getting others to want the outcomes you want- co-opts peoples rather coerces them (NYE, 1990a, p.12).
} 
Nye irá dividir as fontes de Soft Power em três elementos principais: (1) a cultura, (2) os valores políticos e (3) a política internacional.

(1) Cultura engloba os aspectos da sociedade, e seus valores, na medida em que eles são atrativos para os outros, como os países que buscam reproduzir o modo de vida e as tradições das nações mais bem vistas. A cultura de um país pode ser divulgada pelo comércio, intercâmbio cultural e turismo.

(2) Os valores políticos podem ser definidos na forma como as instituições e os valores de um país são compreendidos no exterior.

(3) Política internacional é o conjunto de condições que faz com que um país tenha uma legitimidade maior que outros na hora do debate internacional podendo, com a sua opinião sobre determinado assunto, ser referência para os demais.

O Soft Power é constituído por todos aqueles elementos que não estão relacionados com o poder econômico e militar (COOPER, 2004). Existe a dificuldade para medir sua influência de forma objetiva e criar categorias que possam isolar seus elementos, já que é constituído por fatores em grande parte imateriais, que não podem ser medidos e pesados da mesma forma que o tamanho de um exército ou a capacidade de produção de bombas, mas no mundo contemporâneo a materialidade do Hard Power também deve ser relativizada, vide o ataque cibernético da Rússia, possivelmente, influenciando nas eleições presidenciais dos EUA em 2016 e da França em 2017, criando uma atmosfera de terror na internet.

Mesmo com esta imaterialidade partir-se-á do pressuposto que há importantes aspectos na teoria do Soft Power e ela pode servir de elemento de análise na política internacional, não na sua totalidade, mas na sua particularidade. Neste artigo analisaremos a influência dos Megaeventos Esportivos como forma de desenvolver o 
Soft Power do país sede. Utilizaremos como estudo de caso, a forma como a mídia internacional abordou o Brasil na Copa do Mundo de Futebol de 2014.

\section{Raízes Teóricas do Soft Power}

Nos estudos de Soft Power a nação é a protagonista das relações internacionais, agindo de forma coesa e racional. Mesmo que os sujeitos não-estatais se desataquem cada vez mais no cenário internacional, sua relação ainda é dada pela influência ou não sobre os estados nacionais (COOPER, 2004; CAMPBELL; MICHAEL, O'HANLON, 2006). Segundo Morgentau (2003, p; 173), “a política é a manifestação de uma luta pelo poder, e é justificado em termos éticos, legais ou biológicos”.

A centralidade do conceito de poder, na teoria política e de Nye (1990b), particularmente, é uma característica da escola realista. Para esta escola as relações entre as diferentes nações são dadas como disputas por poder, que no final é o objetivo último de cada país, sendo esse poder medido principalmente em termos militares e econômicos.

Nye irá entender o poder como algo amplo, nesse sentido os diferentes elementos de empoderamento não poderiam ser transferidos de uma nação para a outra como simples cópia, nem sua existência é garantia direta de influência e coerção. Há elementos intangíveis que são importantes na política e nas relações de poder internacional (HUANG; DING, 2006, p.33) ${ }^{5}$. Nas novas relações internacionais, pósqueda do muro de Berlim, a teoria de poder como algo mais fluído faz sentido. A teoria

\footnotetext{
${ }^{5}$ Nye's theory is different from the realist paradigm in several important aspects. Firstly, he does not assume that power resources are fungible. Not only is power at different levels not always convertible, but power resources do not automatically translate into effective influence or compliance. Put differently, those best endowed with power do not always obtain their desired outcomes. According to Nye, power is defined as "the possession of capabilities or resources that can influence outcomes," and "the ability to influence the behavior of others to get the outcomes one wants. (HUANG; DING, 2006, p.33)
} 
de Nye se mostra também uma boa ferramenta para a análise do novo cenário internacional e o crescimento dos BRICS, principalmente da China (HOLSTI, 1985, p.4) ${ }^{6}$.

No texto de 1977, "Power and Interdependence: World Politics in Transition", Nye, juntamente com Robert O. Keohane, utilizará o conceito de interdependência, fundando o que hoje é considerada a escola neoliberal institucional das relações internacionais, entendendo que na maioria das vezes os estados, mesmo aqueles em expansão, preferem utilizar as instituições existentes para a busca de poder e prestígio internacional.

O conceito de interdependência legitima o Soft Power, pois considera que a coerção militar e econômica não são os únicos meios, nem os mais utilizados, na busca por prestígio e influência internacional, permitindo que os sujeitos busquem estes objetivos por outros caminhos, muitas vezes legítimos, e possam ascender dentro da ordem estabelecida sem necessariamente destruir suas instituições e acordos (SINGER, 1969; LAFER, 1982; HOLSTI, 1985; NYE, 2004).

\section{O Soft Power e os Megaeventos Esportivos}

Os megaeventos, hoje, gozam de grande visibilidade no mundo acadêmico, não precisando aqui discutir o que são os megaeventos, o que os caracteriza, o processo histórico de consolidação do esporte como megaevento. Muitos pesquisadores trazem estas questões com maior profundidade do que poderemos desenvolver aqui. Há uma ampla bibliografia que pode ser consultada, inclusive nas referências deste artigo, para dar base teórica sobre este universo.

\footnotetext{
6 “one nation's search for security often leaves its current and potential advisories insecure, any nation that strives for absolute security leaves all others in the system absolutely insecure, and it can provide a powerful incentive for arms races and other types of hostile interactions" (HOLSTI, 1985, p. 4).
} 
Em termos genéricos os megaeventos sempre foram utilizados como propaganda política de um país, os exemplos emblemáticos são: a) os Jogos Olímpicos de 1936 em Berlim; b) os Jogos disputados no período da Guerra Fria. Findado a Guerra Fria os jogos se consolidariam como mega espetáculos do século XXI, extrapolaria os conceitos de Guy Debord sobre a Sociedade do Espetáculo.

Neste universo que nos encontramos, em uma sociedade de capitalismo avançado que busca a civilização, mas vive suas contradições mais pungentes como a fome e o terrorismo de Estado e Religioso.

O país sede, desde o anúncio do evento, ficará no foco da mídia internacional, sendo assunto recorrente no noticiário de um grande número de países que incorporaram estes espetáculos como componente cultural. Temas como o andamento das obras, segurança dos turistas, gastos, atrasos e protestos são discutidos quase diariamente.

Durante o evento os olhos do mundo se voltam para o país, que além de ser ocupado por um grande número de turistas, também atrai a imprensa internacional e seus leitores. Apesar de o foco principal ser o futebol, a audiência mundial acaba, mesmo que indiretamente, tendo contato com outros aspectos do país, e estes aspectos é que nos interessam.

A noção de Soft Power oferece diversas ferramentas para entendermos esse novo fenômeno social, os megaeventos esportivos (MANZENREITER, 2010; PREUSS; CHRISTIAN, 2011; GRIX; LEE, 2013). Como discutimos anteriormente, na abordagem de Nye as relações internacionais passam por uma mudança que leva à diminuição da influência dos elementos Hard e um aumento dos elementos Soft. 
O Soft Power está intrinsicamente relacionado com a esfera pública ${ }^{7}$, tendo este aporte uma importância fundamental nessa nova abordagem das relações internacionais. A evolução das tecnologias de comunicação e o advento da internet o tornam mais complexo, já que a informação é produzida em quantidade e abrangência universal, sendo a disputa por visibilidade muito difícil, com os mais diversos sujeitos, dos maiores aos menores, lutando para serem ouvidos tanto no âmbito nacional quanto internacional (GRIX; LEE, 2013, p.8) ${ }^{8}$.

Nesse novo cenário os megaeventos esportivos apresentam uma oportunidade para o país divulgar sua imagem para o mundo e, através dos valores universais dos jogos, atingir uma audiência global (GRIX, LEE, 2013; GRIX, BRANNAGAN, HOULIHAN, 2015).

Não há consenso sobre o sucesso do Soft Power nos megaeventos esportivos, o artigo de Manzenreiter (2010) "The Beijing Games in the Wesern Imagination: The Weak Power of Soft Power", aponta, a partir de dados globais, o fraco impacto da transformação de percepção das pessoas do Oeste (ocidente) sobre a sociedade chinesa na questão dos direitos humanos, liberdade de expressão e garantias institucionais, no entanto, apresenta dados positivos sobre a cultura chinesa, o turismo, a pungência econômica e infraestrutura (2010, p.45). No mesmo sentido, em questionar o poder do Soft Power, Brannagan e Giullianotti (2014) discute a forma que o Qatar está utilizando

\footnotetext{
${ }^{7}$ Utilizamos como aporte teórico o livro de Jürgen Habermas "Mudança Estrutural da Esfera Pública", onde define-se: "A esfera pública pode ser descrita como uma rede adequada para a comunicação de conteúdos, tomadas de posição e opinião; nela os fluxos comunicativos são filtrados e sintetizados a pontos de condensarem opiniões públicas enfeixadas em temas específicos. Do mesmo modo que o mundo da vida tomado globalmente, a esfera pública se reproduz através do agir comunicativo implicando apenas o domínio de uma linguagem natural" (HABERMAS, 2014, p.93).

${ }^{8}$ As communicative practices, international sporting events are important opportunities for hosting states to showcase their sameness (which is not only a core component of attractiveness to others but also a source of legitimacy global agents). By successfully hosting a major sporting event to showcase shared social norms and sameness, the state can enhance its international prestige and attractiveness in order to boost its agency in international politics (GRIX; LEE, 2013, p.8).
} 
Copa do Mundo para se firmar como nação amiga do ocidente ${ }^{9}$, que por um lado, geram graves crises locais, mas por outro lado, há o aumento significativo das transações multinacionais e incremento do turismo. Portanto, apontamos aqui uma análise de via de mão dupla: os megaeventos podem ou não incrementar o Soft Power do país sede, sendo falso a afirmação que o megaevento esportivo por si só traria ganhos na política internacional.

Como já foi exposto, Nye divide as fontes de Soft Power em três categorias principais: a cultura, valores políticos e política internacional (NYE, 2008). Os megaeventos esportivos, segundo a perspectiva que adotamos, apresentam uma grande oportunidade para estar no "spotlight" da política internacional, nesses três aspectos.

A cultura é divulgada pelo evento com um todo, com um grande número de turistas vagando pelo país e tendo contatos com suas mais diferentes manifestações, nem sempre positivas. Os eventos de abertura e encerramento constituem o ápice, com apresentações cada vez mais cinematográficas que têm como objetivo mostrar os feitos e as qualidades da nação (MANZENREITER, 2010).

Os valores políticos são divulgados na organização da competição e no funcionamento das instituições. Com a proximidade do evento as instituições, o respeito aos direitos humanos e a situação de vida no país passam por um escrutínio da opinião pública internacional, aliado a ONGs e movimentos sociais que utilizam a visibilidade do momento para divulgar suas causas (JENNINGS, 2014) ${ }^{10}$.

Na política internacional o resultado dos jogos é menos evidente. O país sede pode ganhar nesse aspecto, pois a visibilidade dada às suas instituições e à sua cultura

\footnotetext{
9 "Soft Power and Soft Disempowerment: Qatar, Global Sport and football's 2022 Word Cup finals".

${ }^{10}$ Bulletin Journal of Sport Science and Physical Education n.70, may 2016, Special Feature, "The Olympics and Paralympics in Brazil: Who Take the Prize"; "Brasil em Jogo: o que fica das olímpiadas?" (JENNINGS, 2014).
} 
no período pode garantir um novo prestigio internacional. Esse aspecto, porém, está ligado ao desempenho dos outros dois, a cultura e os valores políticos

Avaliar o Soft Power dos eventos é muito complicado já que, pela sua importância cada vez maior, sediá-los envolve mudanças nos mais diversos aspectos do país, desde a mobilidade urbana e a habitação, até políticos e jurídicos (PREUUS, 2007, p.68). No campo do Soft Power, o gasto de bilhões de dólares, o suposto lucro e uma audiência massiva não representam, por si só, o sucesso da empreitada, podendo resultar em enormes fracassos (ZIAKAS, 2015; PREUSS, 2015) ${ }^{11}$.

\section{Os BRICS, os Megaeventos Esportivos e o Soft Power}

Brasil, Rússia, Índia, China, e posteriormente África do Sul, são os países representados pela sigla BRICS, cunhada incialmente como BRIC pelo então diretor do grupo Goldman Sachs, Jim O’Neil, em 2001 no relatório Building Better Global Economic BRICs, em que afirmava que essas nações em desenvolvimento estariam caminhando para se tornarem grandes potências mundiais.

As previsões se mostraram corretas com esses países, assim como outras nações em desenvolvimento, experimentando um crescimento vertiginoso, provocando mudanças na balança de poder mundial.

Os cinco países, se analisados apenas no aspecto Hard, são potências mundiais, têm grande capacidade militar, sendo que China, Índia e Rússia são potências nucleares. Os BRICS estão na vanguarda dos mais diversos campos da tecnologia, desde a exploração de petróleo até indústria aeroespacial, possuem mercados consumidores de

\footnotetext{
${ }^{11}$ Existem controvérsias sobre os benefícios sociais e coletivos dos megaeventos esportivos, sugerimos dois artigos introdutórios, o primeiro aponta que não há benefícios sociais, e o segundo aponta os benefícios. (1) "For the benefic for all? Devoping a critical perspective in mega-event leverage (ZIAKAS, 2015); (2) "A framework for identifying the legacies of a mega sport event" (PREUSS, 2015);
} 
grande vulto, são líderes regionais incontestes e estima-se que, até 2030, Índia, China e Brasil estejam entre as quatro maiores economias do mundo.

A posse de tamanho poder econômico e militar não impede que, nas relações internacionais modernas, esses países não consigam exercer o poder de maneira tranquila, sendo vistos com muita desconfiança pelas outras nações, ou como sujeitos de menor expressão. Fatores como o sistema político, visto como antidemocráticos ou uma democracia frágil em todos eles, o não comprometimento com os direitos humanos e uma atuação econômica agressiva fazem com que essas nações tenham dificuldade de exercer seu Soft Power de maneira eficiente.

A China é o caso emblemático dessa situação, segunda maior economia do mundo, maior população, um exército de grande capacidade e detentora de uma história milenar tem sua ascensão no cenário internacional vista com grande desconfiança, sendo encarada como um rival em potencial e uma força desestabilizadora na política mundial, o que faz com que o país tenha muita dificuldade em fazer valer sua agenda. Nos últimos anos a noção de Soft Power ganhou destaque, tanto na academia quanto na política chinesa, como um possível meio de melhorar a imagem do país (DING 2010; MANZENREITER, 2010).

Nesse ambiente os megaeventos esportivos foram vistos pelas lideranças destas nações como uma chance de mostrar ao mundo o desenvolvimento do país, sua capacidade organizacional e, através do ideal universal dos jogos, mostrar-se como uma nação que age de acordo com as regras internacionais (HUANG; DING, 2006; NAURIGHT, 2004; MILLINGTON; DARNELL, 2014). Portanto, até 2018 os BRICS serão, ou terão sido, sede de três Copas do Mundo (África do Sul, Brasil e Rússia), de uma edição dos Jogos Olímpicos de Inverno (Rússia), de dois Jogos Olímpicos de verão 
(China e Brasil). E a Índia sediou os Commonwealth Games. Particularmente, o Brasil segundo Almeida et al. (2005) e Vidigal (2005) mudou sua atuação diplomática, procurando um papel mais central no cenário internacional por meio dos jogos. Portanto, não somente o Brasil como estas nações utilizaram os megaeventos esportivos como forma de ampliar sua atuação no cenário mundial, seja para incrementar seu Soft Power, fortalecer os parceiros econômicos, ampliar o turismo de negócio e educacional, bem como, os visitantes curiosos.

\section{Descrição do Método de Pesquisa}

Para analisar o conteúdo das reportagens e relacionar as possíveis interferências no Soft Power, utilizamos a interpretação e revisão bibliográfica e a análise de conteúdo. Com Gueraldi (2005) utilizamos as categorias propostas de aplicação do Soft Power na política externa brasileira. Com Campos (2004) utilizamos as ferramentas de análise temática e categorização, tendo por base os estudos de Bardin (1979) e, por último, Duarte e Barros (2005) com a técnica de coleta de dados em mídias. Cabe registrar que há trabalhos que analisam o Soft Power por meio de jornais, estes foram utilizados como inspiração da pesquisa e da coleta de dados (GRIX; BRANNAGAN, HOULIHAN, 2015; BRANNAGAN, GIULIANOTTI, 2014; MANZEIREITER, 2010).

Algumas inquietações nos moveram a fazer está pesquisa: como as manifestações brasileiras, na literatura e arte, são reconhecidas no cenário internacional? As belezas naturais, os pontos turísticos, e os locais para desfrutar de boa música e boa comida, assim como a hospitalidade do brasileiro são importantes para os estrangeiros? Os valores políticos como os problemas gerais de infraestrutura, a relação entre poder e megaeventos, aparecerão nos jornais? Como é vista a eleição presidencial no cenário 
pós-manifestações das jornadas de junho de 2013? Os problemas de corrupção que afetam diferentes partidos políticos serão discutidos? Haverá um fortalecimento da imagem das instituições no Brasil? Na questão da política internacional, o Brasil demonstrará suas credenciais para uma maior legitimidade na hora do debate internacional em áreas estratégicas?

Para interpretar como se deu essa cobertura foram analisadas 699 reportagens de nove jornais de diferentes línguas (inglesa, francesa e espanhola), os mais acessados da internet no período. A escolha destes jornais foi feita pelo site Alexa, empresa responsável por medir o tráfego na internet, que produz o ranking dos quinhentos sites mais acessados no mundo. Os jornais foram: $\mathrm{CNN}\left(57^{\circ}\right), \mathrm{BBC}\left(64^{\circ}\right)$, Daily Mail $\left(96^{\circ}\right)$, New York Times $\left(126^{\circ}\right)$, The Guardian $\left(147^{\circ}\right)$, El Pais $\left(373^{\circ}\right)$, El Mundo $\left(412^{\circ}\right)$, Le Monde, $\left(445^{\circ}\right)$, Le Figaro $\left(452^{\circ}\right)$. O período de análise escolhido foi entre os dias 11/06/2014 e 15/07/2014, três dias antes de iniciar a Copa do Mundo de 2014 até três dias depois de terminada.

Utilizamos como critério de exclusão a não participação do país na Copa do Mundo, pois isso gera um interesse muito menor na imprensa local, já que o número de jornalistas e turistas desses países também é muito menor.

Escolhemos esses idiomas por serem consideradas as três línguas com o maior número de falantes não nativos, o que faz com que esses jornais sirvam de fonte não apenas para os leitores de seus respectivos países, mas também para um grande número de pessoas que procuram esses jornais como fonte alternativa de informação.

Foram selecionadas as reportagens contendo a palavra-chave Brasil (Brasil, Brazil, Brésil), sendo escolhidas reportagens que tratassem diretamente do país, descartando as ligadas exclusivamente ao futebol (lesões, táticas, expectativas dos 
jogadores). A partir deste filtro foram selecionadas 699 reportagens, posteriormente separadas em cinco categorias diferentes:

(1) Infraestrutura (INF): Nessa categoria agrupamos as reportagens que trataram da infraestrutura brasileira, seja ela relacionada ao evento ou não, como os meios de transporte, hospedagem e segurança, aprofundando-se em outras áreas alheias ao evento, como saneamento básico, transporte público, urbanização, saúde, segurança pública e educação.

(2) Indicadores Sociais (SOC): A relação entre Brasil, pobreza e violência é recorrente nas mídias internacionais. Nessa categoria separamos as reportagens que trataram de temas relacionados à qualidade de vida da população como, por exemplo, desigualdade, projetos sociais, acesso à justiça.

(3) Cultura (CUL): A percepção dos aspectos culturais de um país no estrangeiro é um elemento chave nas relações internacionais. Nessa categoria agrupamos as reportagens que trataram das diversas manifestações do brasileiro e representações do Brasil. Entram aqui reportagens sobre música, folclore, culinária, literatura e belezas naturais.

(4) Futebol (FUT): O Brasil é conhecido como o país do futebol. Nessa categoria escolhemos as reportagens que trataram da centralidade do futebol na vida do brasileiro, principalmente quando os jornais expressam a noção que o futebol é muito mais que um esporte.

(5) Viabilidade da Copa (VIA): Reportagens que expressam preocupações em relação ao sucesso da copa do mundo e o apoio da população ao evento, como os diversos protestos ocorridos durante a copa. 
(6) Cenas do cotidiano (COT): Nessa categoria foram agrupadas as reportagens que tratam de eventos alheios à copa e às categorias anteriores, como reportagens sensacionalistas, relacionadas mais a interesses do país de origem do veículo do que uma visão do Brasil em si.

Tabela 1- Quantidade de notícias por veículo e por categoria.

\begin{tabular}{c|c|c|c|c|c|c}
\hline Categorias & CUL & FUT & INF & IND & VIA & COT \\
\hline BBC & 57 & 17 & 21 & 14 & 19 & 7 \\
CNN & 5 & 17 & 5 & 9 & 5 & 1 \\
DAILY & 24 & 22 & 43 & 17 & 35 & 17 \\
GUARDIAN & 7 & 3 & 7 & 13 & 19 & 2 \\
NYT & 8 & 9 & 6 & 6 & 14 & 3 \\
LE MONDE & 16 & 15 & 9 & 11 & 31 & 27 \\
LE FIGARO & 2 & 6 & 6 & 1 & 6 & 2 \\
EL PAIS & 12 & 8 & 13 & 16 & 13 & 8 \\
EL MUNDO & 14 & 13 & 9 & 16 & 11 & 2 \\
Total & $\mathbf{1 4 5}$ & $\mathbf{1 1 0}$ & $\mathbf{1 1 9}$ & $\mathbf{1 0 3}$ & $\mathbf{1 5 3}$ & $\mathbf{6 9}$ \\
\hline
\end{tabular}

Fonte: Elaborada pelos autores.

As reportagens, às vezes, podem se referir a mais de uma categoria. Nestes casos escolhemos apenas uma categoria em cada reportagem, privilegiando o seu sentido mais relevante.

Agora passaremos a análise dos jornais, procurando entender como os veículos de imprensa trataram de cada tema especificamente. Para cada tópico selecionamos algumas reportagens específicas, que consideramos exemplares, assim como o seu link para aqueles que queiram conferi-las de forma mais aprofundada.

\section{Análise das Reportagens}

As reportagens analisadas contêm uma variedade de assuntos e pontos de vista, por isso qualquer tentativa de enquadrá-las possui de antemão suas falhas. Reconhecemos também que os jornais analisados diferem em linha editorial, formato e público alvo, cada um deles abordando o tema à sua maneira, com seus preconceitos e 
sua agenda interna. O objetivo deste trabalho, porém, não é construir uma análise aprofundada de cada um, nem fazer um juízo de valor sobre a suposta "precisão" de seu jornalismo, mas procurar entender quais assuntos e abordagens foram mais recorrentes e construir um quadro amplo do que foi a Copa do Mundo para a imprensa estrangeira.

Em relação ao "sucesso do evento", reconhecendo a grande volatilidade dessa categoria, e fonte de grande ansiedade para o público brasileiro, percebemos ao final do evento uma visão extremamente positiva da maioria dos veículos, que seguem um caminho similar.

Primeiro uma tendência dos veículos para, no início do evento, duvidar de sua viabilidade, mostrando preocupação com a infraestrutura, protestos, corrupção, violência. À medida que a Copa transcorria sem incidentes, pelo menos na visão desses meios, sete dos nove jornais analisados dedicaram pelo menos uma reportagem reconhecendo que as previsões catastróficas não iam se realizar, e que mesmo com pequenos problemas a Copa seria um sucesso.

A BBC no artigo "Has Brazil proved World Cup doubters wrong? So far so Good “12 será a mais rápida em reconhecer o sucesso de evento, no dia 16 de junho. New York Times aponta que as desgraças dão lugar a pequenos problemas "At the World Cup, Doomsday Predictions Give Way to Smaller Hiccups in Brazil" ${ }^{13}$, no dia 17 de junho. No dia 21 o espanhol El País afirma que as críticas à organização do evento não eram para tanto, "No era para tanto: El Mundial discurre mejor de lo esperado" ${ }^{14}$. O francês Le Monde ${ }^{15}$ no caderno opinião fala que a improvisação a "la

\footnotetext{
$12 \mathrm{http} / /$ www.bbc.com/news/world-latin-america-27866983

http://www.nytimes.com/2014/06/18/sports/worldcup/at-the-world-cup-doomsday-predictions-giveway-to-smaller-hiccups-in-brazil.html

${ }^{14} \mathrm{http}: / /$ deportes.elpais.com/deportes/2014/06/21/mundial_futbol/1403367068_619144.html

$15 \mathrm{http} / /$ www.lemonde.fr/coupe-du-monde/article/2014/06/21/1-improvisation-a-la-bresilienne-se-revelea-la-hauteur-de-l-evenement_4442780_1616627.html
} 
brésilienne" contornam os problemas iniciais, "L'improvisation à la brésilienne se révèle à la hauteur de l'événement". O The Guardian ${ }^{16}$ seguirá o grupo no dia 27 , destacando uma reportagem das previsões de 2013 e que elas estavam erradas "World Cup 2014: five things they said would go wrong in Brazil". Os mais cautelosos, preferindo fazer um balanço apenas no final do evento, foram o Daily Mail e El Mundo. O Daily no artigo "2014 World Cup is a ball in Brazil as beautiful game wins over sceptics"17 afirmando que a edição foi organizada e que a FIFA ganhou muito dinheiro no Brasil. O El Mundo fará uma reportagem que discute três pontos: (a) problemas sociais brasileiros, (b) seleção ter perdido para a Alemanha e (c) organização dos jogos, no primeiro item discute a desigualdade brasileira, no segundo pergunta se o Brasil ainda é uma potência no futebol, e terceiro afirma que a organização do evento foi excelente ${ }^{18}$. Vale destacar que o El Mundo será o único a embasar sua opinião em dados estatísticos, pontuando que $83 \%$ dos visitantes aprovaram a infraestrutura dos jogos ${ }^{19}$. A $\mathrm{CNN}^{20}$ preferiu uma análise mais sóbria, "How did Brazil handle the World Cup?” discutindo os prós e os contras a copa e o que se esperava para os Jogos Olímpicos de verão de 2016, isto apenas no último dia do evento. O Le Figaro não fez um balanço.

Outro elemento que será amplamente discutido, tendo uma abordagem similar em todos os jornais, será o da desigualdade. Nesse sentido os jornais entenderão a sociedade brasileira como extremamente desigual, tanto em termos socioeconômicos quanto de gênero e etnia.

\footnotetext{
${ }_{17}^{16} \mathrm{http}: / /$ www.theguardian.com/football/2014/jun/27/world-cup-2014-five-things-go-wrong 17 http://www.dailymail.co.uk/sport/worldcup2014/article-2678574/2014-World-Cup-ball-Brazilbeautiful-game-wins-sceptics.html\#ixzz3asmyQJqu.

${ }^{18} \mathrm{http}: / /$ www.elmundo.es/opinion/2014/07/14/53c3058fe2704e237b8b458a.html

${ }^{19} \mathrm{http}: / /$ www.elmundo.es/america/2014/07/15/53c5467322601 dbc0b8b4592.html

${ }^{20} \mathrm{http}$ ://edition.cnn.com/videos/world/2014/07/14/pkg-wc-darlington-brazil-report-card.cnn
} 
A pobreza no Brasil, além da crítica social receberá também outra abordagem, principalmente no caso da favela. Seguindo uma tendência do turismo internacional, muitos elementos da miséria acabam por assumir um papel pitoresco. Os veículos então, muitas vezes, vão se distanciar da visão da favela relacionada com a pobreza para dar ares graciosos ao lugar, que acaba por se tornar um elemento característico da cultura brasileira. Esta abordagem fica nítida em notícias como a da BBC "Rio motorbike ride through favela backstreets. As Brazil basks in the World Cup sunshine, you can get a feel for Rio de Janeiro by taking a hair-raising motorbike ride through its backstreets" ${ }^{21}$, ou do The Guardian "Favela residents make World Cup work for them with home stays for fans" 22, além de ser um dos locais preferidos para se noticiar as comemorações ou decepções com o desempenho do Brasil ${ }^{23}$.

A relação do futebol com o Brasil será um tema recorrente em todos os jornais. Mesmo reconhecendo que nem todos os brasileiros são fanáticos pelo futebol, como no caso da reportagem do El Mundo que aponta a saída de muitos brasileiros ao exterior no período da Copa, "Los brasileños escapan del Mundial hacia Uruguay" ${ }^{24}$, ou no caso da CNN com o artigo "Brazil 2014: Exploding the myths of sun, samba, soccer" ${ }^{25}$ que discute a diversidade de elementos do Brasil do século XXI, os jornais sempre acabarão, em algum momento caindo na suposta relação única da modalidade com o país, que pode ser representada na publicação do Daily Mail "The colourful lives inside footballmad Brazil" 26 que caracteriza a população brasileira e sua aderência ao futebol. Enquanto as reportagens anteriores caracterizavam um estrato social que podem viajar

\footnotetext{
${ }^{21} \mathrm{http}: / /$ www.bbc.com/news/world-latin-america-27815624

${ }^{22} \mathrm{http}: / / \mathrm{www}$. theguardian.com/football/blog/2014/jun/23/favela-residents-world-cup-home-stays-fans

$23 \mathrm{http}: / / \mathrm{www}$. lemonde.fr/coupe-du-monde/video/2014/07/09/soiree-de-cauchemar-dans-une-favela-derio-de-janeiro_4453819_1616627.html

${ }^{24} \mathrm{http}: / /$ www.elmundo.es/internacional/2014/06/25/53aaf18322601 dba658b4590.html

${ }^{25} \mathrm{http}$ ://edition.cnn.com/2014/06/13/opinion/brazil-sun-sex-soccer/

26 http://www.dailymail.co.uk/video/news/video-1099617/The-colourful-lives-inside-football-madBrazil.html
} 
ou ter outras opções de lazer, o Daily acaba afirmando que o futebol é o grande elemento da cultura popular brasileira. As abordagens irão se repetir, destacando o futebol como saída da pobreza ${ }^{27}$, o possível efeito que a derrota avassaladora da seleção brasileira poderia ter nas eleições presidenciais $^{28}$ e como tanto nas grandes cidades como no interior todos jogam futebol ${ }^{29}$.

A categoria futebol foi construída pelo interesse dos jornais em saber se o Brasil é o país do futebol e onde ele se insere na cultura brasileira, veículos como a BBC abordaram a forma que as seleções foram recepcionadas, trazendo a linguagem futebol como fator de aproximação do Brasil com o mundo. Percebemos, porém, uma abordagem mais crítica ao futebol nos jornais latinos, como a possibilidade de o Brasil ser o país do futebol por que as crianças jogam para conseguir uma oportunidade na vida. Talvez por conhecer mais a realidade o El Mundo traz uma visão bem lucida sobre a mercantilização do futebol no Brasil e os problemas da corrupção na Confederação Brasileira de Futebol ${ }^{30}$. De todas as reportagens a que entendemos com maior relação ao Soft Power são as que discutiram a relação da eleição presidencial e o Brasil vencer ou não a Copa do Mundo. Em democracias avançadas espera-se que a escolha de um presidente de um país tenha relação com a proposta política do candidato bem como os valores do partido e do grupo de referência, na nossa análise, aos jornais colocarem uma relação direta entre a Copa do Mundo e as eleições brasileiras, mostra-nos como a democracia brasileira é frágil, pensando na segunda categoria propostas por Nye,

\footnotetext{
${ }^{27} \mathrm{http}: / /$ elpais.com/elpais/2014/06/09/planeta_futuro/1402337916_559348.html

$28 \mathrm{http} / / / w w w . l e m o n d e . f r / c o u p e-d u-m o n d e / a r t i c l e / 2014 / 07 / 09 /$ la-presidente-du-bresil-ne-croit-pas-que-ladefaite-ravivera-la-contestation_4454278_1616627.html

29 http://lens.blogs.nytimes.com/2014/07/11/world-cup-brazil-mauricio-lima-lens-blog-worldsglare $/ ? \mathrm{r}=0$

${ }^{30} \mathrm{http}: / /$ www.elmundo.es/comunidad-valenciana/2014/06/19/53a1e999ca474197518b4594.html)
} 
valores políticos, claramente o Brasil não apresenta as características que o coloquem na vanguarda das instituições políticas.

No aspecto da cultura as maiores informações foram em cadernos do turismo, principalmente no caso da $\mathrm{BBC}$, cada cidade sede teve um caderno específico, aumentando significativamente o número de reportagens desta categoria ${ }^{31}$. Pelo fato da $\mathrm{BBC}$ possuir uma rádio, houve um espaço privilegiado para música brasileira ${ }^{32}$. Podemos entender que a cultura brasileira foi valorizada, no sentido de dar subsídios para o viajante. Podendo servir de base para as afirmações que a Copa do Mundo incrementa o turismo no âmbito internacional. Na questão do Soft Power este modelo de criar um cenário paradisíaco valoriza o país, podendo servir de formas de fortalecer aspectos econômicos na política internacional, bem como, criar uma imagem, que vezes não corresponde a realidade, como fez a $\mathrm{CNN}$ ao mitificar a favela ${ }^{33}$. Por meio do link vocês poderão ver os estrangeiros fazendo selfies na rocinha, muito longe das cenas que olhamos diariamente na realidade destes núcleos populacionais desassistidos.

$\mathrm{Na}$ área da cultura também tiveram seu espaço as reportagens sensacionalistas e as aprofundadas, no primeiro caso o Daily Mail seja o maior representante, destacamos a reportagem sobre se tem ou não piranhas nas águas de Manaus ${ }^{34}$. No segundo caso o Le Monde discutiu a cultura brasileira destacando os intelectuais brasileiros como Sérgio Buarque de Holanda e Roberto da Matta $^{35}$ e nomes tradicionais da música brasileira. Os jornais de língua espanhola, talvez pela proximidade cultural da península ibérica aprofundaram mais os temas, trazendo elementos como a cordialidade e a

\footnotetext{
${ }^{31} \mathrm{http}: / / \mathrm{www} \cdot$ bbc.com/news/world-latin-america-27815624

$32 \mathrm{http} / / / \mathrm{www}$. bbc.com/news/world-latin-america-27256168

${ }^{33} \mathrm{http}: / /$ edition.cnn.com/videos/sports/2014/07/02/soares-pkg-world-cup-tours-favelas.cnn

$34 \mathrm{http} / / / w w w . d a i l y m a i l . c o . u k / w i r e s / a p / a r t i c l e-2659242 / B R A Z I L-B E A T-P i r a n h a s-N o-p r o b l e m-M a n a u s-$ beach.html

${ }^{35} \mathrm{http}: / /$ www.lemonde.fr/economie/article/2014/06/23/quelques-cliches-du-bresil_4443467_3234.html
} 
miscigenação, bem como o papel do negro, dos índios e dos mestiços em construir uma identidade nacional.

$\mathrm{Na}$ infraestrutura os jornais apresentam duas realidades, uma do evento que tende a ser positiva e outra das condições de vida dos brasileiros, fazendo severas críticas ao modelo econômico e social adotado no Brasil. Logicamente que questões pontuais tiveram seu espaço como as enchentes nas cidades de Natal e Recife, e à frente destas reportagens noticiou-se muito a queda do viaduto em Belo Horizonte. Um aspecto interessante revelado pela pesquisa é que muitos dos elementos que a imprensa brasileira considerava fonte de grande embaraço para o país, como trânsito, hotelaria, segurança e aeroportos, não tiveram o mesmo destaque na imprensa internacional.

Nos Indicadores Sociais o Brasil mostrou as suas credenciais de país dos contrastes e do subdesenvolvimento. Nos jornais de língua inglesa, pela discussão intensa sobre o processo de gentrificação em Londres, deu-se muita ênfase às desapropriações $^{36}$. Os jornais franceses e espanhóis concentraram suas críticas à desigualdade racial e social, bem como mostrando inconsistência em discursos oficiais sobre igualdade racial. Coube espaços específicos para discutir o trabalho análogo ao escravo no Brasil, o mercado de drogas e as favelas ${ }^{37}$. Em São Paulo a forma como exploramos os imigrantes bolivianos ${ }^{38}$ teve um caderno especial no El País, o título do artigo é bem sugestivo "El sueño americano, versión brasileña”. Particularmente, o The Guardian abordou assuntos como Direitos Humanos, pobreza, desmatamento, desalojamento das famílias para construir estádios, direitos indígenas e discutiu o racismo no Brasil e a violência policial, não somente nos protestos como também no

\footnotetext{
${ }^{36}$ http://edition.cnn.com/2014/06/13/opinion/brazil-sun-sex-soccer/

http://www.dailymail.co.uk/video/femail/video-1102005/Prince-Harry-gets-close-look-effects-drugaddiction-Brazil.html)

${ }^{38} \mathrm{http}: / /$ www.elmundo.es/solidaridad/2014/07/14/53c41b4b22601d071e8b4592.html
} 
cotidiano $^{39}$. Pensando na categoria de Nye sobre Soft Power o Brasil apresenta as inconsistências de sociedades pouco desenvolvidas, o que pesaria em decisões fundamentais como na Assembleia da ONU. Um país com problemas graves tem condições de estar à frente de ações intergovernamentais, dispendendo recursos que o país não possui, ou gasta de maneira pouco eficiente?

Viabilidade da Copa, categoria construída devido aos protestos, teve grande repercussão na mídia internacional. Os problemas causados ao povo brasileiro por sediar a Copa do Mundo não foram tratados como sendo de responsabilidade exclusiva do governo brasileiro, seguindo a tendência presente em todos os jornais analisados. A FIFA e seu modelo de negócios divide a culpa pelas eventuais injustiças e transtornos causados à população brasileira ${ }^{40}$. Houve destaque à prisão de parceiros da FIFA ligados à venda ilegal de ingressos ${ }^{41}$. Esta categoria pode dividir as análises e concentra muitas perspectivas. O povo conseguir protestar é importante para o Soft Power, mas a violência policial denigre as instituições que tem função de zelo aos cidadãos. Prender membros da FIFA deu credenciais importantes à Polícia Federal no cenário internacional.

\section{Considerações Finais}

Para estas considerações gostaríamos de responder algumas questões apontadas na introdução, e tentar sistematizar uma resposta coerente a partir da literatura consultada e pesquisa nos jornais selecionados. O megaevento oferece de fato, aos países sede, oportunidades de se ingressarem como um porta voz político representando uma região? Apenas se o país já possui as instituições fortes e democracias

\footnotetext{
${ }^{39} \mathrm{http}: / /$ www.theguardian.com/world/2014/jun/15/dying-to-save-amazonian-rainforest-brazil

${ }^{40} \mathrm{http} / / / \mathrm{www}$. bbc.co.uk/programmes/p020jxrf

${ }^{41} \mathrm{http}: / /$ www.bbc.com/news/world-latin-america-28240135
} 
representativas, pelas análises feitas aqui é falso pensar que nações como África do Sul, Rússia ou China podem reverter o olhar estrangeiro pós-evento. No caso do Brasil a tão sonhada cadeira permanente no Conselho de Segurança da ONU pode ser conquistada com ações políticas internacionais como são os megaeventos? Não. Pois o Brasil se afasta dos valores das Nações Unidas pela sua violência policial e institucional, bem como conflitos raciais, indígenas e gênero

Definir o sucesso ou não de um megaevento evento, como já discutimos, é uma tarefa extremamente complexa, envolvendo uma série de variáveis eventualmente contraditórias.

Este trabalho procurou demonstrar a validade do Soft Power como uma categoria de análise das relações internacionais e aplicá-la na compreensão e análise da cobertura jornalística da Copa do Mundo do Brasil de 2014. O primeiro grande problema encontrado é pensar se um acontecimento de curto prazo (Megaeventos) pode interferir na política internacional instantaneamente? Não.

No caso brasileiro não há elementos concludentes para pensarmos o incremento do Soft Power de forma absolutamente segura, pois existem apontamentos positivos e negativos, cabendo uma nova análise pós-megaeventos no Brasil, talvez incluindo a realização da Olimpíada de 2016, analisando as políticas internacionais e seus sucessos e insucessos.

Nos casos da China e Rússia, diferente do Brasil, ações tomadas pelos governos durante o período do evento tiveram impactos negativos instantâneos, como a dificuldade de acesso à internet pelos correspondentes na China, inclusive com correspondentes que foram embora por não conseguir realizar seu trabalho, ou a 
aprovação de leis homofóbicas durante os Jogos de Inverno na Rússia, onde vários atletas desistiram de participar do evento.

A Copa da FIFA de 2014 deu uma visibilidade ao Brasil no cenário internacional. Deste modo, pensamos que o Brasil conseguiu se expor. Mas não obteve o sucesso de alavancar seu Soft Power. Por três motivos, violência, desigualdade social e fragilidade democrática.

Porém não podemos negar que houve uma divulgação da diversidade cultural, com vários aspectos antes obscuros entrando em cena, inclusive resinificando um aspecto polêmico, abordando a favela com um olhar pitoresco e representante da cultura brasileira.

As manifestações culturais brasileiras, como a literatura e artes, foram menos citadas que as belezas naturais, pontos turísticos, e locais para desfrutar de boa música e boa comida. Assim como a hospitalidade do brasileiro. Neste caso, fica evidente que o apelo aos aspectos culturais tem o sentido não de pensar os valores da nação, mas de "vender" a imagem do Brasil ao exterior enquanto mercadoria de consumo na agenda turística internacional. Neste caso específico parece que o valor cultura, discutido por Nye e seus colaboradores, deixa a desejar, pois a cultura deve ser pensada como os valores do povo, sua forma de enxergar a realidade e lidar com os conflitos cotidianos. Para Habermas, trata-se de pensar a esfera pública como a forma que os sujeitos sociais, no Brasil, constroem sua relação e apoiam a formação de uma sociedade civil organizada, que respeita a diferença. Fica claro que os jornais estudados mostraram ao mundo um país extremamente desigual e com presença do racismo institucional, algo que há certa resistência de admitirmos enquanto nação. 
Os jornais mostraram que as instituições funcionam, mas apontaram que elas são seletivas no seu funcionamento, de acordo com o local visitado e o nível de instrução da população. A violência policial assustou os correspondentes internacionais, principalmente nos primeiros dias de protestos, antes de iniciar a Copa do Mundo. Reportagens com Movimentos Sociais Organizados demonstram, por outro lado, a liberdade de manifestação, fato este que pode ser visto como positivo se comparado a outros países subdesenvolvidos, pois uma sociedade que almeja a igualdade deve permitir que as pessoas se posicionem frente aos problemas do governo.

$\mathrm{Na}$ questão de infraestrutura, dois tópicos importantes que estavam na agenda no Brasil não foram mencionados: os aeroportos e os congestionamentos. A relação entre poder e futebol aparece com a reeleição da presidente Dilma Roussef. Há um fortalecimento da imagem das instituições no Brasil, principalmente com a prisão de membros da FIFA, mas ainda se fala na violência policial e a corrupção endêmica no país.

$\mathrm{Na}$ questão da política internacional, o Brasil ao demonstrar sua hospitalidade mostrou credenciais para uma maior legitimidade na hora do debate internacional em áreas estratégica, como a economia, porém perde legitimidade na área dos direitos humanos, violência contra a mulher, racismo e pobreza extrema, indicadores que apontam fragilidade na política internacional e na visibilidade do Brasil no exterior.

\section{REFERÊNCIAS}

ALMEIDA, B.; BASTOS, B. Displacement and Gentrification in the 'City of Exception': Rio de Janeiro Towards the 2016 Olympic Games. Journal of Sport Science and Physical Education. n. 70, s.3, p.54-60, 2016. Special Feaure: The Olympics and Paralympics in Brazil: who takes the prize? 
ALMEIDA, B. et al. J. Rationales, rhetoric and realities: FIFA's World Cup in South Africa 2010 and Brazil 2014. International Review for the Sociology of Sport, v.50, n.3, p.265-282, 2005.

BARCA, A. J. No era para tanto. El País. São Paulo, 21 Jun. 2014, p.1. Mundial Fútbol. Disponível em: https://deportes.elpais.com/deportes/2014/06/21/mundial_futbol/1403367068_619144.h tml. Acesso em: 03 mar. 2017.

BARDIN, L. Análise de Conteúdo. Lisboa, Edições 70, 1979.

BORDENJUNE, S. At the World Cup, Doomsday Predictions Give Way to Smaller Hiccups in Brazil. NYT. New York. 17 Jun. 2014, p.1. Word Cup. Disponível em: https://www.nytimes.com/2014/06/18/sports/worldcup/at-the-world-cup-doomsdaypredictions-give-way-to-smaller-hiccups-in-brazil.html. Acesso em: 03 mar. 2017.

BOURCIER, N. L'improvisation à la brésilienne se révèle à la hauteur de l'événement. Le Monde. Rio de Janeiro, 21 Jun. 2014. Brésil 2014, p.1. Disponível em: https://www.lemonde.fr/coupe-du-monde/article/2014/06/21/1-improvisation-a-labresilienne-se-revele-a-la-hauteur-de-1. Acesso em: 03 mar. 2017.

BRANNAGAN, P.M., GIULliANOTTI, R. Soft Power and Soft Disempowerment: Qatar, Global Sport and football's 2022 Word Cup finals. Leisure Studies, v.10, p. 1$17,2014$.

BRASIL, fracaso deportivo ¿y de país? El Mundo. Madrid. 14 jul. 2014. Opínion, p.1 Disponível

em: https://www.elmundo.es/opinion/2014/07/14/53c3058fe2704e237b8b458a.html. Acesso em: 03 mar. 2017.

BRAZIL BEAT: Piranhas? Daily Mail. Manaus. 17 jun. 2014. Article, p.1. Disponível em: https:/www.dailymail.co.uk/wires/ap/article-2659242/BRAZIL-BEAT-PiranhasNo-problem-Manaus-beach.html. Acesso em: 03 mar. 2017.

BRAZIL: The Last World Cup? BBC. London. 14 jun. 2014. In the Balance, p.1. Disponível em: https://www.bbc.co.uk/programmes/p020jxrf. Acesso em: 03 mar. 2017.

CAMPBELL, K. M., MICHAEL E., O'HANLON. Hard power: The new politics of national security. Basic Books, 2006.

CAMPOS, C. J. Método de Análise de conteúdo. Ferramenta para a análise de dados qualitativos no campo da saúde. Revista Brasileira de Enfermagem, v.57, n.5, p.611614, 2004.

CAPPELLI, D. Los brasileños escapan del Mundial hacia Uruguay. El Mundo. Montevideo. 25 jun. 2014, Internacional, p.1. Disponível em: https:/www.elmundo.es/internacional/2014/06/25/53aaf1 8322601dba658b4590.html. Acesso em: 03 mar. 2017. 
THE COLOURFUL lives inside football-mad Brazil. Daily Mail. London. 12 jun. 2014. Cup, p.1. Disponível em: https:/www.dailymail.co.uk/video/news/video1099617/The-colourful-lives-inside-football-mad-Brazil.html. Acesso em: 03 mar. 2017.

COOPER, R. Hard power, soft power and the goals of diplomacy. In: American power in the 21st century p.167-180, 2004.

DAMO, A. S. Dinheiro público em megaeventos esportivos: a eficácia de uma justificativa inconsistente. Ciência e cultura, v. 68, p. 27-31, 2016.

DARLINGTON, S. How did Brazil handle the World Cup? CNN. London. 14 jul. 2014. World, p.1. Disponível em: https://edition.cnn.com/videos/world/2014/07/14/pkg-wcdarlington-brazil-report-card.cnn. Acesso em: 03 mar. 2017.

DAVIES, W. Has Brazil proved World Cup doubters wrong? So far so Good. BBC. London, 16 Jun. 2014. Latin America \& Caribbean, p.1. Disponível em: http://www.bbc.com/news/world-latin-america-27866983. Acesso em: 03/03/2017.

DING, S. Analyzing Rising Power from the Perspective of Soft Power: a new look at China's rise to the status quo power. Journal of Contemporary China, v.19, n.64 p.255-272, 2010.

DUARTE, J., BARROS, A. Métodos e Técnicas de Pesquisa em Comunicação. São Paulo, Atlas, 2005.

EL $83 \%$ de los extranjeros que visitó Brasil aprobó la organización del Mundial. El Mundo. Rio de Janeiro. 15 jul. 2014. Mundial, p.1 Disponível em: https://www.elmundo.es/america/2014/07/15/53c5467322601dbc0b8b4592.html.

Acesso em: 03 mar. 2017.

FREEMAN, H. Favela residents make World Cup work for them with home stays for fans The Guardian. Rio de Janeiro. 23 jun. 2014. World Cup 2014, p.1. Disponível em: https:/www.theguardian.com/football/blog/2014/jun/23/favela-residents-world-cuphome-stays-fans. Acesso em: 03 mar. 2017.

GONZALES, D. Soccer in Brazil, and outside the world's game. NYT. São Paulo. 11 jul. 2014. World, p.1. Disponível em: https://lens.blogs.nytimes.com/2014/07/11/worldcup-brazil-mauricio-lima-lens-blog-worlds-glare/?_r=0. Acesso em: 03 mar. 2017.

GRIX, J., BRANNAGAN, P.M., HOULIHAN, B. Interrogating States Soft Power Strategies: a case study of Sports Mega-Events in Brazil and the UK. Global Society, v.29, n.3, p.463-479, 2015.

GRIX, J., LEE, D. Soft Power, Sports Mega-Events and Emerging States: The Lure of the Politics of Attraction. Global Society. v.27 n.4, p.521-536, 2013.

GUERALDI, R. G. A Aplicação de poder brando (soft power) na política externa brasileira. São Paulo, Coleções EBAPE - Dissertações, Mestrado Acadêmico em Administração, 2005. 
HABERMAS, J. Mudança Estrutural da Esfera Pública. São Paulo, Editora Unesp, 2014.

HIERRO, L. Infancia + favelas = fútbol. El País. Madrid. 16 jun. 2014. Brasil, p.1. Disponível em: https://elpais.com/elpais/2014/06/09/planeta_futuro/1402337916_559348.html. Acesso em: 03 mar. 2017.

HOLSTI, K. J. The Dividing Discipline: Hegemony and Diversity in International Theory. London Book, 1985

HUANG, Y.; DING, S. Dragon's underbelly: An analysis of China's soft power. East Asia. v. 23, n.4, p.22-44, 2006.

INTERNATIONAL COUNCIL OF SPORT SCIENCE AND PHYSICAL EDUCATION. BULLETIN. The Olympics and Paralympics in Brazil: who takes the prize? Journal of Sport and Physical Education. n. 70, 2016.

JENNINGS, A. Brasil em Jogo: o que fica da copa e das olímpiadas? São Paulo, Boitempo, Carta Maior, 2014.

JIMÉNEZ. Y. El sueño americano, versión brasileña. El Mundo. São Paulo. 14 jul. 2014. Solidariedad, p.1. Disponível em: https://www.elmundo.es/solidaridad/2014/07/14/53c41b4b22601d071e8b4592.html. Acesso em: 03 mar. 2017.

KEOHANE, R. O.; NYE, J. S. Power and interdependence: world politics in transition. Little, Brown, 1977.

LA PRÉSIDENTE du Brésil ne « croit pas » que la défaite ravivera la contestation En savoir plus sur. Le Monde. Paris. 09 jul. 2014. Brésil 2014, p.1. Disponível em: https://www.lemonde.fr/coupe-du-monde/article/2014/07/09/la-presidente-du-bresil-necroit-pas-que-la-defaite-ravivera-la-

contestation_4454278_1616627.html\#sDgcrHhhfeTwBqd0.99. Acesso em: 03 mar 2017.

LADYMAN, I. World Cup ball Brazil beautiful game wins sceptics. Daily Mail. London. 2 Jul. 2014. Word Cup, p.1. Disponível em: https://www.dailymail.co.uk/sport/worldcup2014/article-2678574/2014-World-Cupball-Brazil-beautiful-game-wins sceptics.html\#ixzz4aIEnWDpv Acesso em: 03 mar. 2017.

LAFER, C. Paradoxos e Possibilidades: Estudos Sobre a Ordem Mundial e Sobre a Política Exterior do Brasil num Sistema Internacional em Transformação. Rio de Janeiro, Nova Fronteira, 1982.

MANHEIM, J. B. Rites of passage: The 1988 Seoul Olympics as public diplomacy. The Western Political Quarterly, v.43, n.2, p.279-295, 1990. 
MANZENREITER, W. The Beijing games in the western imagination of China: The weak power of soft power. Journal of Sport \& Social Issues v.34, n.1, p.29-48, 2010.

MAYOR, P. El fútbol y Brasil. El Mundo. Valencia. 19 Jun. 2014. Comunidad Valenciana, p.1. Disponível em: https:/www.elmundo.es/comunidadvalenciana/2014/06/19/53a1e999ca474197518b4594.html. Acesso em: 03 mar. 2017.

MILLINGTON, R., DARNELL, S. R. Constructing and contesting the Olympics online: the internet, Rio 2016 and the politics of Brazilian development. International Review for the Sociology of Sport, v.49, n.2, p.190-210, 2014.

MORGENTAU, H. A Política entre nações: a luta pelo poder e pela paz. Imprensa Oficial do Estado de São Paulo, 2003.

NAURIGHT, J. Global Games: Culture, Political Economy and Sport in the Globalized World of the 21st Century. Third World Quarterly, v.25, n.7, p.1325-1336, 2004.

NYE, J. S. Bound to lead: the changing nature of American power. New York. Basic Book, 1990a.

NYE, J. S. Soft Power: Foreing Policy. n.80, special issues twentieth anniversary. Washigtonpost, p.153-171, 1990b.

NYE, J. S. Soft power: The means to success in world politics. Public Affairs, 2004

NYE, J. S. Public Diplomacy and Soft Power. Annals AAPSS, n.616, p.94-111, 2008.

PEREIRA, A. Brazil 2014: Exploding the myths of sun, samba, soccer. CNN. São Paulo. 13 Jun. 2014. Opinion, p.1. Disponível em: https://edition.cnn.com/2014/06/13/opinion/brazil-sun-sex-soccer. Acesso em: 03 mar. 2017.

PREUSS, H. The conceptualisation and measurement of mega sport event legacies. Journal of sport \& tourism. v.12 n.3-4 p.207-228, 2007.

PREUSS, H., CHRISTIAN A. Signaling through the 2008 Beijing Olympics-Using Mega Sport Events to Change the Perception and Image of the Host. European Sport Management Quarterly v.11, n.1 p.55-71, 2011.

PREUSS, H. The conceptualisation and measurement of mega sport event legacies. Journal of sport \& tourism. v.12 n.3-4 p.207-228, 2015.

PRINCE HARRY sees the effects of drug addiction in 'Cracolandia'. Daily Mail. São Paulo. 16 jun. 2014. News, p.1. Disponível em: https://www.dailymail.co.uk/video/femail/video-1102005/Prince-Harry-gets-close-lookeffects-drug-addiction-Brazil.html. Acesso em: 03 mar. 2017.

QUELQUES clichés du Brésil. Le Monde. Paris. 23 jun. 2014. Économie, p.1. Disponível em: https:/www.lemonde.fr/economie/article/2014/06/23/quelques-clichesdu-bresil_4443467_3234.html. Acesso em: 03 mar. 2017. 
RIO motorbike ride through favela backstreets. BBC. Rio de Janeiro. 14 Jun. 2014. Latin America \& Caribbean, p.1 Disponível em: https:/www.bbc.com/news/worldlatin-america-27815624. Acesso em: 03 mar. 2017.

ROLNIK, Raquel. Jogos Olímpicos e direito à moradia adequada. Cienc. Cult. [online]. 2016, vol.68, n.2 [cited 2017-01-20], pp. 31-36

SINGER, D. The Level of Analysis Problem in International Relations. In: ROSENAU, J. International Politics and Foreign Policy. New York, The Free Press, p. 20-29, 1969.

SOARES, I. A walking tour of Rio's favelas. CNN. Rio de Janeiro. 02 jul. 2014. World Cup, p.1. Disponível em: https://edition.cnn.com/videos/sports/2014/07/02/soares-pkgworld-cup-tours-favelas.cnn. Acesso em: 03 mar. 2017.

SOIRÉE de cauchemar dans une favela de Rio de Janeiro. Le Monde. Rio de Janeiro. 09 jul. 2014, Brésil 2014, p.1. Disponível em: https://www.lemonde.fr/coupe-dumonde/video/2014/07/09/soiree-de-cauchemar-dans-une-favela-de-rio-dejaneiro_4453819_1616627.html. Acesso em: 03 mar. 2017.

VIDIGAL, C. E. Brasil: potência cordial? A diplomacia brasileira no início do século XXI. Revista Eletrônica de Comunicação, Informação \& Inovação em Saúde, v.4, n. 1 p.23-36, 2005.

WATTS, J. VIEIRA, K. Dying to save the Amazonian rainforest. The Guardian. Amazonas. 15 jun. 2014. Brazil, p.1. Disponível em: https:/www.theguardian.com/world/2014/jun/15/dying-to-save-amazonian-rainforestbrazil. Acesso em: 03 mar. 2017.

WILSON, E. J. Hard power, soft power, smart power. The annals of the American academy of Political and Social Science. v.616, n.1, p.110-124, 2008.

WORLD CUP 2014: five things they said would go wrong in Brazil. The Guardian. London. 27 Jun. 2014. World Cup 2014, p.1. Disponível em: https://www.theguardian.com/football/2014/jun/27/world-cup-2014-five-things-gowrong. Acesso em: 03 mar. 2017.

WORLD CUP Brazil city guide: Recife. BBC. Recife. 12 jun. 2014. Latin America \& Caribbean, p.1. Disponível em: https://www.bbc.com/news/world-latin-america27256168. Acesso em: 03 mar. 2017.

WORLD CUP tickets: Ray Whelan and 11 others indicted. BBC. Rio de Janeiro. 10 jul. 2014. Latin America \& Caribbean, p.1. Disponível em: https://www.bbc.com/news/world-latin-america-28240135. Acesso em: 03 mar. 2017.

ZIAKAS, Vassilios. For the benefit of all? Developing a critical perspective in megaevent leverage. Leisure Studies, v.4, n.6, p.689-702, 2015. 


\section{Endereço dos Autores:}

Marco Bettine Almeida

Rua: Arlindo Bettio, 1000 - Vila Guaraciaba

São Paulo - SP - 03.828-000

Endereço Eletrônico: marcobettine@gmail.com

Diego Gutierrez

Rua: Arlindo Bettio, 1000 - Vila Guaraciaba

São Paulo - SP - 03.828-000

Endereço Eletrônico: diego.monteirogutierrez@gmail.com 